\title{
Apoptosis during chick inner ear development: some observations by TEM and TUNEL techniques
}

\author{
B. Avallone, G. Balsamo, S. Trapani, and F. Marmo \\ Department of Genetics, General and Molecular Biology, University of Naples “Federico II”, Naples, Italy
}

Accepted: 16/7/01

Key words: apoptosis, inner ear, chick embryo, chick, TEM, TUNEL

\section{SUMMARY}

In order to clarify the occurrence, distribution and possible role of apoptosis during inner ear development, the ultrastructural aspects (by TEM) (at 9-19 incubation day and 1 day after hatching) and the distribution of the apoptotic phenomenon (by the TdTmediated dUTP nick end-labeling technique), were studied in the crista ampullaris of chick embryo at 5-19 days of incubation to hatching and of postnatal 1-day old chick.

We found, in the sensorial epithelium, dark supporting cells in chick embryos and mainly dark hair cells in postnatal chicks, both with ultrastructural features consistent with those of apoptosis. The presence of apoptotic phenomena was confirmed by the TUNEL technique.

According to our findings, it is hypothesized that apoptosis in the inner ear may be involved: 1) at first, in macroscopic remodelling of the membranous labyrinth in early developmental stages, 2) later, in the correct differentiation of the hair and of the supporting cells, leading to characteristic cellular pattern formation and 3) finally, in physiological cell turnover of the postnatal chicken sensorial epithelium of the crista.

\section{INTRODUCTION}

Apoptosis is as much a part of embryonic development as are cell proliferation and differentiation, and constitutes a significant element in the process of embryonic morphogenesis. Hair cell apoptosis is a "natural" event, continuously occurring in vestibular sensory epithelia. "Darkly staining" hair cells and apoptotic bodies have been observed in undamaged vestibular sensory epithelia of non mammalian vertebrates (Jørgensen, 1991), tissues in which there appears to be constant production of hair cells (Cotanche et al., 1994).

Li et al. (1995) have identified a degeneration of hair cells within the epithelium of the guinea pig inner ear, which showed morphological features consistent with those described for apoptosis both in animals treated with an ototoxic antibiotic and in controls.

Our previous studies on the crista ampullaris of the lizard Podarcis s. sicula revealed a type of dark cells, similar to Wersäll (1956) type II sensory cells, restricted to a small area of the crista. These cells might be 1), special sensory cells; 2), different stages of differentiation of sensory cells; or 3), expression of apoptotic phenomena as probably implied by the crista cell turnover (Balsamo et al., 1995). 
Regions of apoptosis were identified in the inner ear of vertebrate embryos by Fekete et al. (1997) and Lang et al. (2000), i.e. in the ventromedial otic vesicle, at the base of the endolymphatic duct and the fusion plates of the semicircular canals. Hot spots of apoptotic cells have been also seen around the sensory organs in the ear of the chick embryo during development (Fekete et al., 1997). Kil et al. (1997) demonstrated the presence of apoptotic phenomena in chick utricle and saccule and Nishikori et al. (1999) studied apoptosis during inner ear development in human and mouse embryos.

The aim of the present work was therefore to study the occurrence, distribution and possible role of apoptosis in the morphogenetic remodelling and differentiation of the developing chick inner ear, investigating the ultrastructural aspects by TEM and the distribution of apoptosis phenomena by the TdT-mediated dUTP nick end-labeling (TUNEL) technique.

The studies were carried out on the crista ampullaris of chick embryo from 5 days of incubation to hatching, as well as in postnatal chicks.

\section{MATERIALS AND METHODS}

Transmission electron microscopy (TEM) studies were carried out on chick embryos at 9,11,13,15,19 incubation days (ID) as well as on 1-day-old chicks. Four embryos for each developmental stage and two 1-day-old chicks were used.

The heads of chick embryos on $5^{\text {th }}-11^{\text {th }}$ ID and the temporal bones since the $13^{\text {th }}$ ID were fixed in $2.5 \%$ glutaraldehyde in $0.1 \mathrm{M}$ phosphate buffered saline (PBS), $\mathrm{pH} 7.4$ for $3 \mathrm{~h}$ at $4^{\circ} \mathrm{C}$. The chicks were anaesthetized before killing and the heads were subjected to the same treatment as the embryos.

After microdissection of the vestibular end organ, the specimens were rinsed in PBS, and post-fixed in $1 \% \mathrm{OsO}_{4}$ in the same buffer for $1 \mathrm{~h}$ at $4^{\circ} \mathrm{C}$. After several rinses in PBS, the specimens were dehydrated, embedded in Epon 812 resin and serially sectioned in a Super Nova Leica Ultratome. Ultra- thin sections were placed on copper grids, and counterstained with uranyl acetate and lead citrate. Specimens were observed and photographed with a Philips CM12 electron microscope.

\section{TUNEL technique}

Studies were carried out on chick embryos at $5,7,9,11,13,15,17,19$ ID to hatching and in postnatal 1-day-old chicks.

Four embryos for each developmental stage and two postnatal chicks were used. The heads of embryos on $5^{\text {th }}-11^{\text {th }}$ ID and the temporal bones since the $13^{\text {th }} \mathrm{ID}$, were fixed in $4 \%$ paraformaldehyde in PBS, pH 7.4 for $4 \mathrm{~h}$ at $4^{\circ} \mathrm{C}$, and rinsed overnight in same buffer at $4^{\circ} \mathrm{C}$.

The heads of embryos on $5^{\text {th }}-11^{\text {th }}$ ID and since $13^{\text {th }} \mathrm{ID}$, after microdissection, only the vestibular end organ were dehydrated, embedded in paraffin wax and serially sectioned in the transverse plane at $5 \mu \mathrm{m}$. Sections were dewaxed and rehydrated according to standard procedure.

Slides were treated with $4 \mu \mathrm{g} / \mathrm{ml}$ protease K (Sigma, St. Louis, MO, USA) in $10 \mathrm{mM}$ Tris/ $\mathrm{HCl}, \mathrm{pH}$ 7.4 for $8 \mathrm{~min}$ at room temperature (r.t.) in order to strip nuclei; slides were also treated with $0.3 \%$ $\mathrm{H}_{2} \mathrm{O}_{2}$ in $0.15 \mathrm{M}$ Tris buffered saline (TBS) for 30 min in order to block endogenous peroxidase activity, and processed by the "in situ cell death detection kit, POD" (Boehringer Mannheim, Mannheim, Germany) in a humidified chamber.

Negative control tissue sections were incubated with TUNEL label only $\left(60 \mathrm{~min}\right.$ at $\left.37^{\circ} \mathrm{C}\right)$ instead of using the TUNEL reaction mixture.

Positive control tissue sections were incubated with Dnase I (Boehringer Mannheim, Mannheim, Germany) $70 \mu \mathrm{g} / \mathrm{ml}$ for $10 \mathrm{~min}$ at r.t. just before adding the TUNEL reaction mixture.

The sections were subsequently counterstained with $1 \%$ methyl green in $0.2 \mathrm{M}$ sodium citrate, $\mathrm{pH}$ 4.1 .

Light observations were made with a Zeiss Axioskop microscope using KS 300 software (Kontron electronic) to acquire microscopic images, and

Fig. 1 - a) Crista ampullaris of chick embryo on the $13^{\text {th }}$ ID. Dark cell with nuclear and cytoplasmic condensation and fragmentation in the process of "budding" into many apoptotic bodies (arrows). Note one sensorial cell (S.C.). Scale bar $=2.3 \mu \mathrm{m}$. b) Crista ampullaris of chick embryo on the $15^{\text {th }}$ ID. Apoptotic cell in the process of "budding" into apoptotic bodies (arrow). Scale bar = $2.3 \mu \mathrm{m}$. c) Crista ampullaris of chick embryo on the $15^{\text {th }}$ ID. Dark cell with clumping of nuclear chromatin that lies against the nuclear membrane. Scale bar $=2.3 \mu \mathrm{m}$. d) Crista ampullaris of 1 day old chick. Hair cell with dark cytoplasmic matrix, condensed nucleus, with initial "budding"(arrow), intact mitochondria and dilated endoplasmic reticulum. Scale bar $=2.3 \mu \mathrm{m}$. 
Imp. Avallone 3-09-1956 10:31 Pagina 55
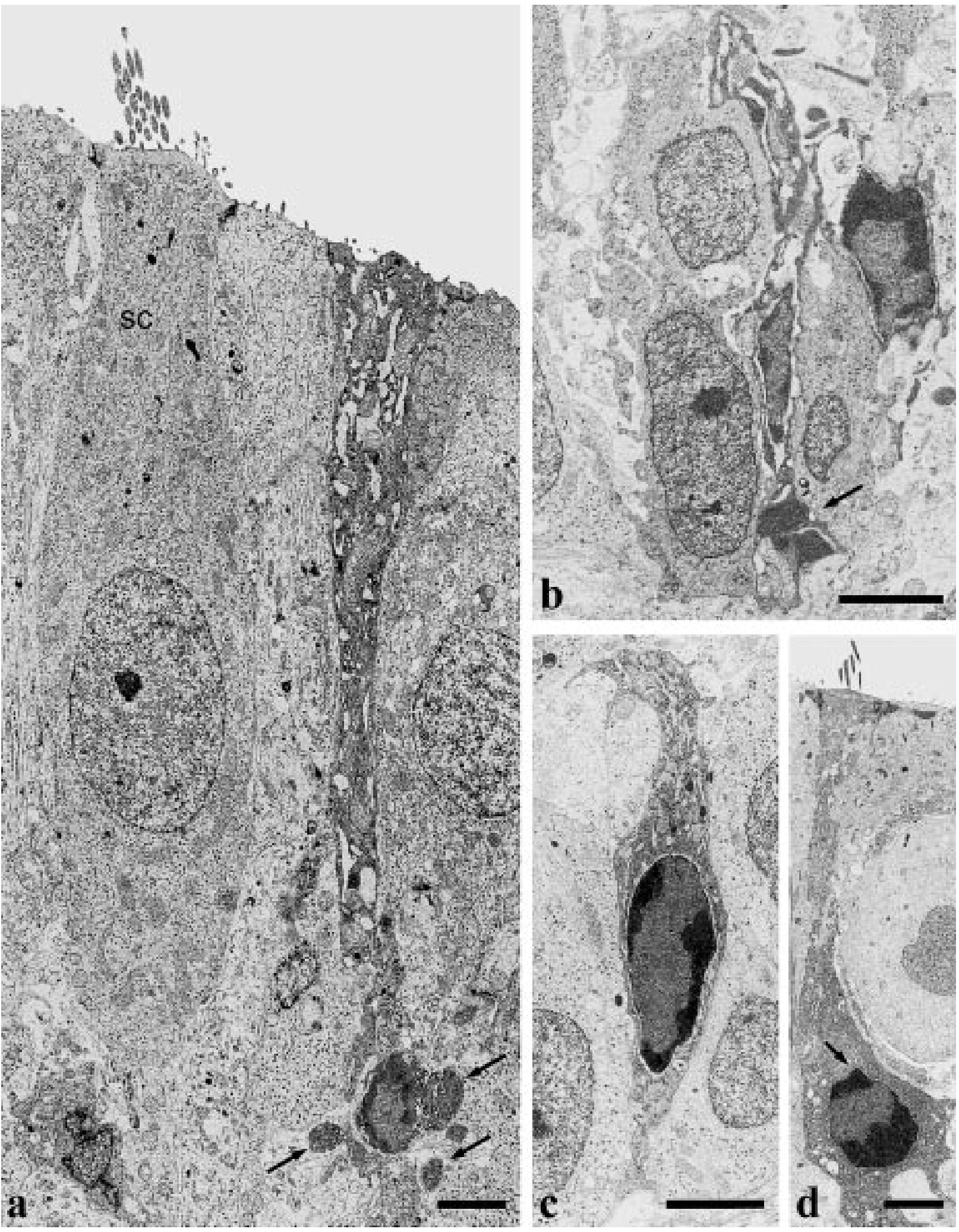
Propalette 8000 (Polaroid) for digital colour film recording.

According to current Italian law (art. 7 D.L. 116/92) the research plan and animal experimentation procedure have been communicated to the "Centre for veterinary service for the protection of animals used for scientific experimentation" of the University of Naples "Federico II". The communication has been made in adherence to CEE guidelines 86/609/CEE.

\section{RESULTS}

TEM observations indicate that chick embryos on the $9^{\text {th }}$ and $11^{\text {th }}$ ID do not show dark cells either in the sensory epithelium of the crista or in the "dark cells area". In this area, cells with a darker cytoplasmic matrix appear in embryos on the $13^{\text {th }} \mathrm{ID}$. In embryos at later stages of development, these cells differentiate until they assume the well-known morphology of the dark cells of this area of the crista.

Cells with a dark cytoplasmic matrix appear in the sensory epithelium zone of embryos for the first time on the $13^{\text {th }} \mathrm{ID}$, and they increase in number in embryos on the $15^{\text {th }}$ ID. These cells show supporting cell morphology and are observed side-by-side with sensory and light supporting cells (Fig. 1a). These dark cells 1), show a progressive increase in the electron density of both the nucleus and cytoplasm which was accompanied by a clumping of nuclear chromatin lying against the nuclear membrane, 2), are of smaller size than light counterparts, 3), tend to have an irregular, ill-defined contour and 4), appear narrow in their central part (Fig. 1a). The cells rest on the basal membrane (Fig. 1c). The nucleus is always basally located (Figs. 1a-c). However, mitochondria appear to be intact and the endoplasmic reticulum dilated (Figs. 1a-c). Occasionally, nuclear fragments, together with dark constituents of cytoplasm including intact organelles (apoptotic bodies), can be observed (Figs. 1a,b).

The number of these dark cells progressively declines until the $19^{\text {th }}$ ID. We also found, in all examined stages, supporting cells with a cytoplasmic matrix at various degree of electrondensity (Figs. 1a-c), which showed various tonalities of grey. At hatching, we also observed dark hair cells which often showed morphological features consistent with those described for apoptosis (Fig. 1d).
The TUNEL technique showed that the apoptotic phenomena are widely distributed, and localized in clusters in the epithelia of the inner ear bud as well as in the surrounding mesenchymal tissues in embryos on the $5^{\text {th }}$ and $7^{\text {th }}$ ID (Figs. 2 a-c).

Previously identified regions of cell death have been also observed in the present investigation at the base of the endolymphatic duct (Fig. 2b) and the thick rim and the thin part of the utricular outpocket in the semicircular canals (data not shown).

In the next stages, until the $13^{\text {th }} \mathrm{ID}$, the number of labelled cells progressively decreases, both in the epithelia, where it is still diffuse in the sensory zone, and in the connective tissue (Fig. 2d).

In embryos on the $15^{\text {th }}$ ID and until the $19^{\text {th }}$ ID, the apoptotic phenomena are very attenuated and present only in few and isolated cells (Fig. 2e). In successive stages, and after hatching, there are very few, prevalently sensorial, TUNEL-labelled cells (Fig. 2f).

\section{DISCUSSION}

The cells we observed by TEM are a new type of dark cells, different from the well known "dark cells" which are present in the crista at the level of the "dark cells area" (Watanuki et al., 1970; Igarashi, 1989; Igarashi et al., 1989; Balsamo et al., 1995) and that are thought to be secretory cells that produce endolymph (Kimura, 1969).

Morphological features of the cells described by us in the crista epithelium, during development, are similar to these described, after gentamicin-induced damage, in the vestibular epithelia (Li et al., 1995), and in outer hair cells in the organ of Corti (Forge, 1985) which have been suggested to be apoptotic.

Apoptosis is thought to be a means of removing unwanted or damaged cells without disturbing tissue integrity or inducing inflammation. Morphological features and the positivity to the TUNEL technique in our studies confirm the presence of apoptotic phenomena.

Programmed cell death was found in many regions of the developing inner ear of the chicken. Regions of cell death previously identified in vertebrate ear have been confirmed, including the base of the endolymphatic duct and the fusion plates of the semicircular canals.

Our findings confirmed that apoptosis, in early embryonic development stages, may be involved in 

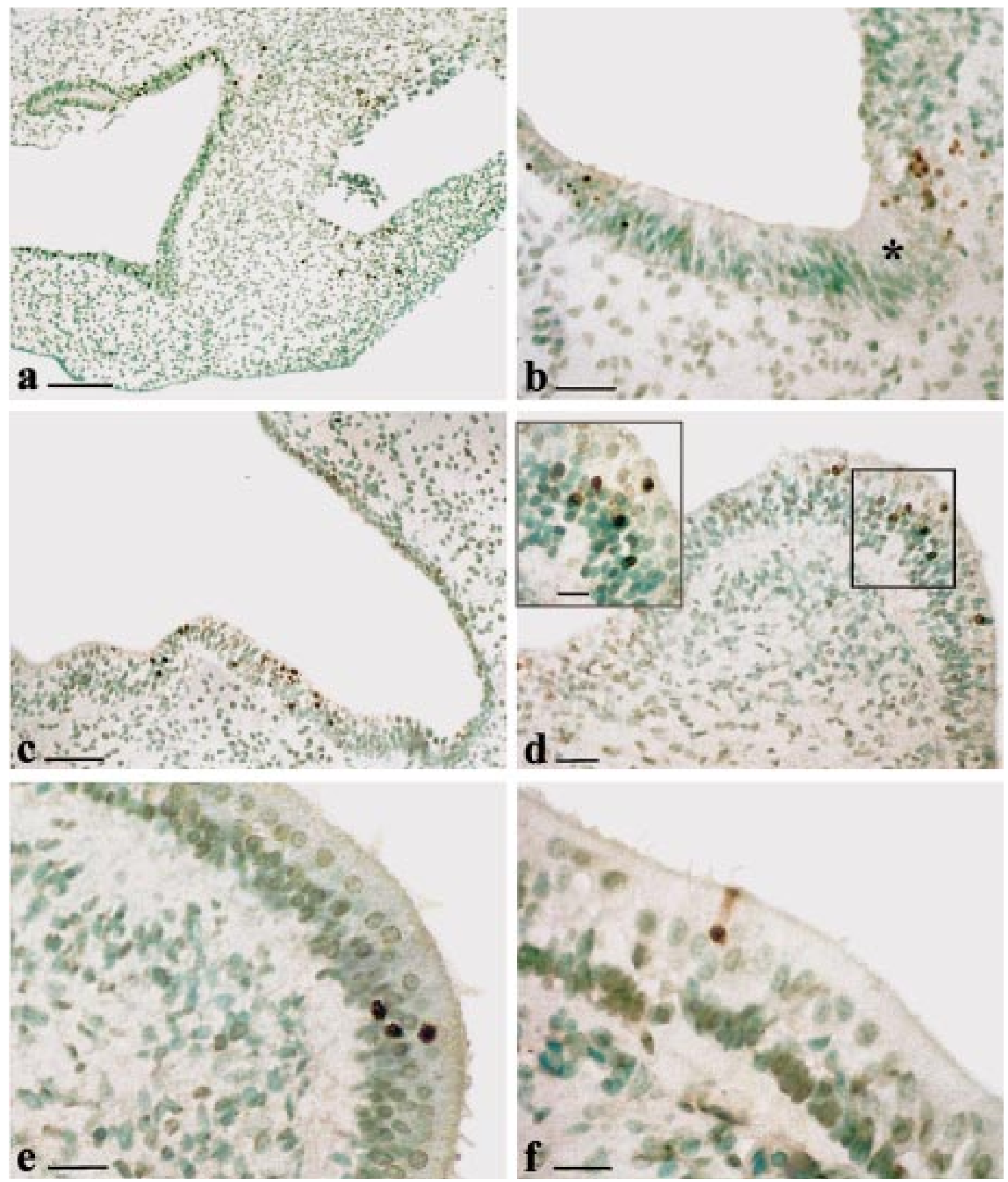

Fig. 2 - a) Chick embryo on the $5^{\text {th }}$ ID. Apoptosis is widely distributed and localized in clusters in the epithelia of the inner ear bud as well as in the surrounding mesenchymal tissues. Scale bar $=77 \mu \mathrm{m}$. b) Chick embryo on the $7^{\text {th }}$ ID. Apoptotic phenomena are localised in clusters at the base of endolymphatic duct epithelium (asterisk). Scale bar $=24 \mu \mathrm{m}$. c) Chick embryo on the $7^{\text {th }}$ ID. Apoptosis is localized in clusters in the sensorial epithelium of utricular macula bud. Scale bar $=40 \mu \mathrm{m}$. d) Chick embryo on the $13^{\text {th }}$ ID. Apoptotic phenomena are still diffused in sensory epithelium of the crista ampullaris. Scale bar $=20 \mu \mathrm{m}$. Inset. High magnification of frame area. Scale bar $=9 \mu \mathrm{m}$. e) Chick embryo on the $15^{\text {th }}$ ID. TUNEL positivity is present in few cells of the crista ampullaris. Scale bar $=16 \mu \mathrm{m}$. f) Chicken 1day after hatching. Apoptosis is present in one sensorial cell TUNEL-labelled in the crista ampullaris. Scale bar $=13 \mu \mathrm{m}$. 
macroscopic remodelling of the membranous labyrinth, and, in fact, such a morphogenetic event is accompanied by localized hot spots of cell death.

In successive stages (11-13 ID) of embryonic development, the fading out of apoptotic phenomena may indicate their involvement in the processes of sensory and supporting cells differentiation, which lead to the formation of the peculiar cellular pattern in the sensorial epithelium.

One mechanism for such cell diversification is lateral inhibition, whereby a cell that is becoming committed to a particular pathway of differentiation inhibits its immediate neighbours from doing likewise (Corwin et al., 1991; Lewis, 1991).

The models proposed by Goodyear et al. (1995) for differentiation of the hair and supporting cells are various: in some cases, perfectly precise, self perpetuating mosaics are formed, but in others, false seeding sites are present, which do not lead to a self perpetuating mosaic and contain irregularities where the cells generated at the different sites meet. In agreement with these models, we propose that the dark cells are overproduced cells and, just for this reason, are programmed to die. This hypothesis is supported by the TEM observation that the darkapoptotic cells, morphologically of a supporting type, appear in the sensory epithelia, only when hair cell differentiation is ongoing.

However, during development, apoptosis is a significant mechanism for generating the normal number of cells, and it may be concluded, in agreement with Fekete et al. (1997), that programmed cell death is a general process leading to cellular pattern formation in complex structures, apart from the histotypical tissue type.

Finally, the finding, in later stages of development and after hatching, of apoptosis in few, and mainly in hair cells types, supports the hypothesis that these phenomena are involved prevalently in physiological cell turnover of sensory epithelium, widely demonstrated in almost all vertebrates (Corwin and Cotanche, 1988; Raphael and Miller, 1991; Adler and Raphael, 1996; Baird et al., 1996).

In agreement with Orita et al. (1999), however, we identified a population of inner ear TUNELpositive cells, that could not be regarded as dark or apoptotic, based upon morphological features. In fact, according to Sanders and Wride (1996), the TUNEL technique allows the recognition of cells undergoing DNA fragmentation, before the onset of the alteration in morphology, and in cells that do not show classical apoptotic characteristics. This may explain the greater number of cells that we found to be TUNEL-positive, compared to those showing TEM morphological features consistent with those described for apoptosis. We hypothesize, therefore, that the cells showing at TEM various grey tonality are probably already undergoing DNA fragmentation, but their morphology is not yet completely altered.

\section{ACKNOWLEDGMENTS}

$$
\text { Grant sponsor MURST 40\% - Italy }
$$

\section{REFERENCES}

Adler H.J., and Raphael Y.: New hair cells arise from supporting cell conversion in the acoustically damaged chick inner ear. Neurosci. Lett. 205, 17-20, 1996.

Baird R.A., Steiger P.S., and Schuff N.R.: Mitotic and nonmitotic hair cell regeneration in the bull frog vestibular otolith organs. Ann. N.Y. Acad. Sci. 781, 59-70, 1996.

Balsamo G., Avallone B., Calabrò D., and Marmo F.: The ampullae of the inner ear in the Lizard Podarcis s. sicula. Ultrastructural aspect. Scanning microscopy 9(2), 493-500, 1995.

Corwin J.T., and Cotanche D.A.: Regeneration of sensory hair cells after acoustic trauma. Science 240, 1772-1774, 1988.

Corwin J.T., Jones J.E., Katayama A., Kelley M.W., and Warchol M.E.: Hair cell regeneration: the identities of progenitor cells, potential triggers and instructive clues. In:. Regeneration of vertebrate sensory receptor cells. Wiley, Chichester. CIBA Foundation Symposium 160, 101-130, 1991

Cotanche D.A., Li K.H., Stone J.S., and Picard D.A.: Hair cell regeneration in the bird cochlea following noise damage or ototoxic drug damage. Anat. Embryol. 189, 1-18, 1994.

Fekete D.M., Homburger S.A., Waring M.T., Riedl A.E., and Garcia L.F.: Involvement of programmed cell death in morphogenesis of the vertebrate inner ear. Dev. 124, 2451-2461, 1997.

Forge A.: Outer hair cell loss and supporting cell expansion following chronic gentamicin treatment. Hear. Res. 19, 171$182,1985$.

Goodyear R., Holley M., and Richardson G.: Hair and supporting-cell differentiation during the development of the avian inner ear. J. Comp. Neurol. 351, 81-93, 1995.

Igarashi Y.: Submicroscopic study of the vestibular dark cell area in human fetuses. Acta Otolaryngol. 107, 29-38, 1989.

Igarashi Y., Takeyama I., and Takahashi I.: Melanocytes in vestibular dark cell areas in human fetuses. Acta Otolaryngol. 108, 9-18, 1989. 
Jørgensen J.M.: Regeneration of lateral line and inner ear vestibular cells. In: Regeneration of vertebrate sensory receptor cells. Wiley, Chichester. CIBA Foundation Symposium 160, 151-170, 1991.

Kimura R.S.: Distribution, structure, and function of dark cells in the vestibular labyrinth. Ann. Oto-rhino-laryng. 78, 542-561, 1969.

Kil J., Warchol M.E., and Corwin J.T.: Cell death, cell proliferation, and estimates of hair cell life spans in the vestibular organs of chicks. Hear. Res. 114, 117-126, 1997.

Lang H., Bever M.M., and Fekete D.M.: Cell proliferation and cell death in the developing chick inner ear: spatial and temporal patterns. J. Comp. Neurol. 417, 205-220, 2000.

Lewis J.: Rules for the production of sensory cells. In:. Regeneration of vertebrate sensory receptor cells. Wiley, Chichester. CIBA Foundation Symposium 160, 25-39, 1991.

Li L., Nevil G., and Forge A.: Two modes of hair cell loss from the vestibular sensory epithelia of the guinea pig inner ear. J. Comp. Neurol. 335, 405-417, 1995.
Nishikori T., Hatta T., Kawauchi H., and Otani H.: Apoptosis during inner ear development in human and mouse embryos: an analysis by computer-assisted three-dimensional reconstruction. Anat. Embryol. 200, 19-26, 1999.

Orita Y., Nishizaki K., Sasaki J., Konda S., Kimura N., Nomiya S., Yuen K., and Masuda Y.: Does TUNEL staining during peri-and post-natal development of the mouse inner ear indicate apoptosis? Acta Otolaryngol. Suppl. 540, 22-26, 1999.

Raphael Y., and Miller J.M.: Dual mechanism for production of new hair cells in regenerating avian cochlea. Soc. Neurosci. Abstr. 17, 1214, 1991.

Sanders E.J., and Wride M.A.: Ultrastructural identification of apoptotic nuclei using the TUNEL technique. Histochem. J. 28, 275-281, 1996.

Watanuki K., Kawamoto K., and Katagiri S.: Surface structure of the ampulla of the semicircular canal in the guinea pig. Pract. Oto-rhino-laryng. 32, 137-148, 1970.

Wersäll J.: Studies on the structure and innervation of sensory epithelium of the cristae ampullares in the guinea pig. Acta Otolaryngol. Suppl. 126, 1-85, 1956. 